\title{
The influence of isochronal aging on the mechanical and thermophysical properties of the EN AW-6060 aluminum alloy
}

\author{
U. Stamenković*, S. Ivanov, I. Marković \\ University of Belgrade, Technical Faculty in Bor, Vojske Jugoslavije 12, Bor, Serbia
}

Received December 5, 2018; Revised March 7, 2019

The scope of this paper is the investigation of the effect of precipitation on an EN AW-6060 aluminum alloy by measuring mechanical, physical, and thermal properties. According to the exothermic peaks that appeared on the DSC thermogram and thermal diffusivity curve, parameters for isochronal aging treatment were defined. Thermal, mechanical, physical, and structural properties were investigated during the isochronal aging. The maximal enhancement of mechanical properties was achieved after aging at $230{ }^{\circ} \mathrm{C}$ for 30 min, whereas the most favorable thermal properties were obtained after aging at the same temperature for $60 \mathrm{~min}$. During the aging, the precipitation from the solid solution caused a gradual increase in electrical conductivity. SEM/EDS microstructural investigations confirmed the existence of precipitated phases and provided the insight into their distribution within the microstructure.

Keywords: aluminum alloys, EN AW-6060, aging, heat treatment, thermal properties

\section{INTRODUCTION}

A good combination of properties such as good ductility, high strength-to-weight ratio, formability, corrosion resistance, and non-toxicity makes the aluminum alloys from the 6000 series common industry materials [1, 2]. Besides that, aluminum alloys generally have a good electrical and thermal conductivity with high reflectivity to light and heat [3]. All of these properties are highly affected by the alloy's microstructure. In order to change the microstructure and to improve the properties, alloys from this series are usually subjected to various treatments. Generally, heat treatable aluminum alloys are strengthened by precipitation hardening (aging). The chosen alloy for such investigation is a low-alloyed (lean) EN AW-6060 alloy which is usually strengthened by thermo-mechanical treatment. Many authors have studied the influence of different thermo-mechanical parameters on the properties enhancement. The role of co-clusters on the artificial aging for this alloy was investigated by Pogatscher et al. [4]. Abid et al. [5] discovered that pre-aging enhances the hardening effect. Strobel et al. [6] suggested that prolonged natural aging leads to an increase in hardness and has a positive effect on quench sensitivity. Teichmann et al. [1] investigated the effect of simultaneous deformation and annealing on the precipitation behavior and mechanical properties of this alloy. They confirmed the beneficial influence of simultaneous deformation on the strengthening, i.e., the peak hardness for the deformed alloy was achieved after a shorter annealing time. Milkereit et al. [7] constructed the continuous cooling precipitation

\footnotetext{
* To whom all correspondence should be sent:

E-mail: ustamenkovic@tfbor.bg.ac.rs
}

diagrams for Al-Mg-Si alloys using DSC analysis, SEM/TEM investigations, and hardness measurement. Kim et al. [8] obtained results for thermal diffusivity as a function of temperature and the amount of $\mathrm{Mg}_{2} \mathrm{Si}$ precipitated phase on the quenched samples. Choi et al. [9] investigated the precipitation dependence of thermal diffusivity for $\mathrm{Al}-6 \% \mathrm{Si}-0.4 \% \mathrm{Mg}-0.9 \% \mathrm{Cu}-(\mathrm{Ti})$ alloys with various heat treatments.

According to the literature, it can be concluded that the researchers' focus was on the investigation of the improvement of properties during thermomechanical treatment rather than heat treatment. Also, researchers are mainly focused on investigating the influence of isothermal heat treatment rather than the isochronal one. Therefore, our aim was to investigate the influence of the heat treatment (isochronal aging) alone on the thermal, mechanical, and physical properties of the EN AW6060 aluminum alloy. Based on these investigations, the parameters for isochronal aging treatment involving temperatures higher than conventional and shorter periods of time were defined to provide the optimal values of the studied properties.

\section{EXPERIMENTAL PART}

The EN AW-6060 alloy was chosen for the experimental investigation. The alloy was delivered by "AlCu metali d.o.o." company, in peak-aged state (T6 temper). The chemical composition was determined by using an optical emission spectrometer "Belec Compact Port" and is presented in Table 1. Peak-aged state was removed and O-temper achieved by annealing at $550{ }^{\circ} \mathrm{C}$ for $6 \mathrm{~h}$ in the electric resistance furnace Heraeus K$1150 / 2$. 
Table 1. Chemical composition of the investigated alloy (mass \%)

\begin{tabular}{cccccccc}
\hline $\mathrm{Si}$ & $\mathrm{Fe}$ & $\mathrm{Cu}$ & $\mathrm{Mn}$ & $\mathrm{Mg}$ & $\mathrm{Cr}$ & $\mathrm{Ni}$ & $\mathrm{Zn}$ \\
\hline 0.49 & 0.182 & 0.012 & 0.006 & 0.594 & $<0.003$ & 0.028 & 0.01 \\
\cline { 1 - 3 } & $\mathrm{Pb}$ & $\mathrm{V}$ & $\mathrm{Co}$ & $\mathrm{Sn}$ & $\mathrm{Zr}$ & $\mathrm{Al}$ & \\
\cline { 1 - 6 } 0.005 & $<0.003$ & 0.014 & $<0.003$ & $<0.003$ & $<0.003$ & 98.62 & \\
\hline
\end{tabular}

The samples were solution heat treated at 550 ${ }^{\circ} \mathrm{C}$ for $1 \mathrm{~h}$ and then quenched in ice water in order to obtain the supersaturated solid solution $\left(\alpha_{\text {ssss }}\right)$. Immediately after the quenching, the samples were isochronally aged at different temperatures ranging from $160{ }^{\circ} \mathrm{C}$ to $330{ }^{\circ} \mathrm{C}$, for $30 \mathrm{~min}$ and $60 \mathrm{~min}$. The properties of the aged samples were compared to those of the quenched one (sample Q in Figures).

The sample of the supersaturated EN AW-6060 alloy designated for DSC analysis was investigated with the SDT Q600 (TA Instruments) simultaneous DSC/TGA analyzer by heating the sample up to $600{ }^{\circ} \mathrm{C}$ at the rate of $10^{\circ} \mathrm{C} \mathrm{min}^{-1}$.

Hardness measurements were performed on the VEB Leipzig Vickers hardness tester with a $10 \mathrm{~kg}$ load and a $15 \mathrm{~s}$ dwelling time. In addition, microhardness values were measured using a PMT3 Vickers microhardness tester using 100 gf loads with load duration of $15 \mathrm{~s}$. Both hardness and microhardness measurements followed the ASTM E384 standard [10].

The electrical conductivity tester "Sigma test 2.063 " was used to measure electrical conductivity.

Thermal properties were investigated on the DXF 500 thermal analyzer manufactured by TA Instruments using a flash method. The thermal diffusivity of the quenched sample was studied during the continuous heating at the rate of $10{ }^{\circ} \mathrm{C}$ $\mathrm{min}^{-1}$. Based on the obtained hardness/ microhardness values, three aging temperatures were selected for further thermal diffusivity and thermal conductivity measurements. These properties were measured at room temperature after aging at $160{ }^{\circ} \mathrm{C}, 230^{\circ} \mathrm{C}$ and $330^{\circ} \mathrm{C}$.

Metallographic phase investigations, as well as the distribution of phases, were investigated using the TESCAN Vega 3 LMU scanning electron microscope equipped with an EDS X-act detector by Oxford Instruments.

\section{RESULTS AND DISCUSSION}

\section{DSC analysis}

Fig. 1 shows the DSC thermogram of the quenched EN AW-6060 alloy. The precipitation sequence in $\mathrm{Al}-\mathrm{Mg}-\mathrm{Si}$ alloys is rather complex. The largely accepted sequence can also be seen on the presented thermogram, which is: $\alpha_{\text {ssss }} \rightarrow \mathrm{Mg}: \mathrm{Si}$ clusters $\rightarrow$ G.P. zones $\rightarrow \beta$ ' $\rightarrow \beta$ ' $\rightarrow$ Si (if excess silicon is present $) \rightarrow \beta[7,8,11-16]$. There are six exothermic peaks presented in Fig. 1, some of which are less pronounced due to low calorimetric effect [16].

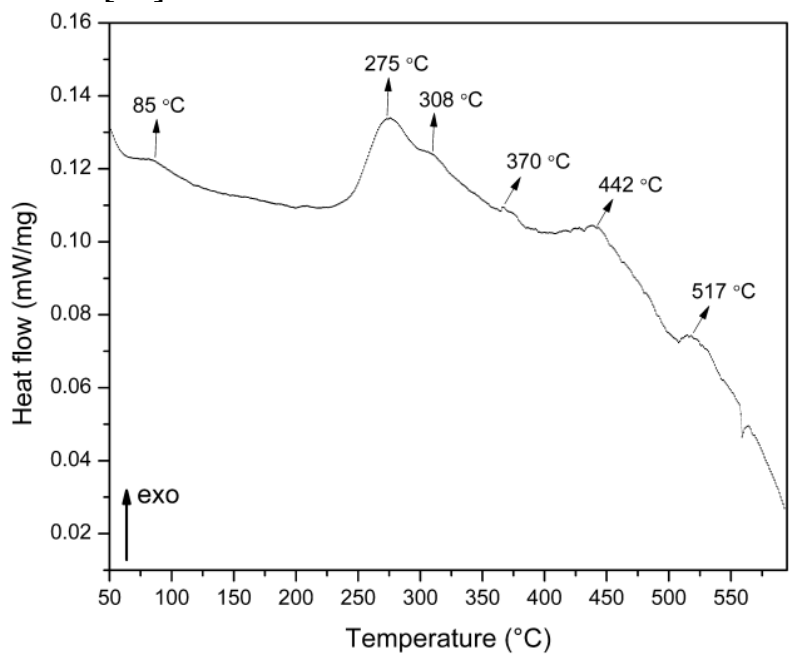

Fig. 1. DSC thermogram for the EN AW-6060 alloy

The peak associated with the $\mathrm{Mg}: \mathrm{Si}$ clustering can be seen at around $85{ }^{\circ} \mathrm{C}[1,7,13,17]$. The formation of metastable $\beta^{\prime \prime}$ and $\beta$ ' precipitates is represented by the two exothermic peaks at $275{ }^{\circ} \mathrm{C}$ and $308{ }^{\circ} \mathrm{C}$, respectively $[5,8,11-18]$. The $\beta "$ metastable phase is the phase that attracted the most attention of the researchers. Marioara et al. [19] characterized it as a needle-like phase with a monoclinic structure that precipitates along the $\langle 100\rangle \mathrm{Al}$ direction, with the unit cell characteristics being: $\mathrm{a}=15.16 \AA, \mathrm{b}=4.05 \AA, \mathrm{c}=$ $6.74 \AA, \beta=105.3^{\circ}$.

The last three exothermic peaks that appear at $370{ }^{\circ} \mathrm{C}, 442{ }^{\circ} \mathrm{C}$, and $517{ }^{\circ} \mathrm{C}$ represent the precipitation of the excess $\mathrm{Si}$ and the formation of the equilibrium $\beta$ phase [11, 12]. Gupta et al. [12] gave the equation for calculating the excess $\mathrm{Si}$ in $\mathrm{Al}-\mathrm{Mg}-\mathrm{Si}$ alloys. For this alloy it is $0.1 \%$. According to Gupta et al. [12], excess Si can have significant influence on the precipitation and strengthening, but in this case the influence is less significant, due to only $0.1 \%$ excess. According to the exothermic peaks that appeared on the DSC thermogram, the temperature of isochronal aging treatment was defined. DSC curves often shift to the right side of the diagram which can be attributed to the sample preparation, measuring equipment and a sample weight that is often very low - in this case about $10 \mathrm{mg}[5,12,17]$. Based on that fact, the temperature ranging from $160{ }^{\circ} \mathrm{C}$ to $330{ }^{\circ} \mathrm{C}$ was chosen. During the defined isochronal 
U. Stamenkovic et al.:The influence of isochronal aging on the mechanical and thermophysical properties of ... treatment, hardness and microhardness values were measured.

Absolute hardness values as a function of aging temperature for the two applied times can be seen in Fig. 2. During the aging at lower temperatures, the hardness values decrease compared to the quenched state. This is most probably due to quenched-in vacancies and solutes causing the movement reduction of dislocations. Afterwards, the hardness gradually increases with the aging temperature reaching the peak age state at $230{ }^{\circ} \mathrm{C}$ for both aging times. This hardening is caused by the precipitation of the metastable $\beta$ " phase, which is the main hardening phase in aluminum alloys from the 6000 series $[5,11,12,20]$.

Compared to the quenched sample which had a $56 \mathrm{HV}_{10}$ hardness value, the peak-aged sample had a hardness value of $85 \mathrm{HV}_{10}$ when aged for $30 \mathrm{~min}$, and $80 \mathrm{HV}_{10}$ when aged for $60 \mathrm{~min}$. That is a $51.7 \%$ relative increase in hardness for the sample aged for $30 \mathrm{~min}$ and a $42.8 \%$ relative increase for the sample aged for $60 \mathrm{~min}$.

As the aging temperature increases the hardness values decrease due to the overaging of the alloy. The change in precipitate type, size, and density, as well as the loss of matrix coherency, leads to the loss of hardening effect [21]. Metastable phases can increase the hardness values, but only for a small amount, as seen in Fig. 2 in the temperature interval from 260 to $330{ }^{\circ} \mathrm{C}$. It can also be seen that in the temperature range from $200{ }^{\circ} \mathrm{C}$ to $330{ }^{\circ} \mathrm{C}$ aging for a shorter time $(30 \mathrm{~min})$ results in higher hardness values than for the longer aging time $(60 \mathrm{~min})$.

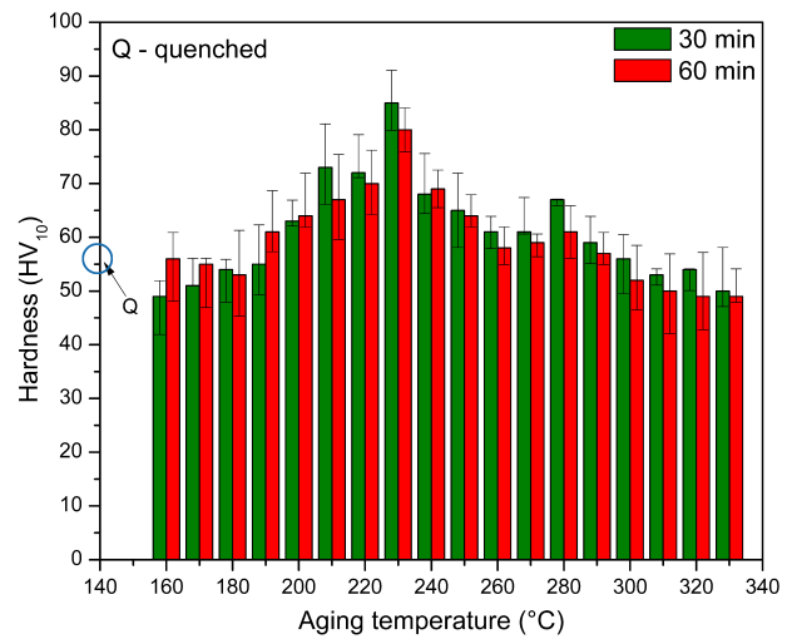

Fig. 2. Hardness values of the EN AW-6060 alloy after the isochronal aging treatment.

\section{Study of mechanical properties}

Microhardness measurements gave somewhat similar conclusions, as shown in Fig. 3. Maximal microhardness values were achieved at $230{ }^{\circ} \mathrm{C}$ for both aging times.

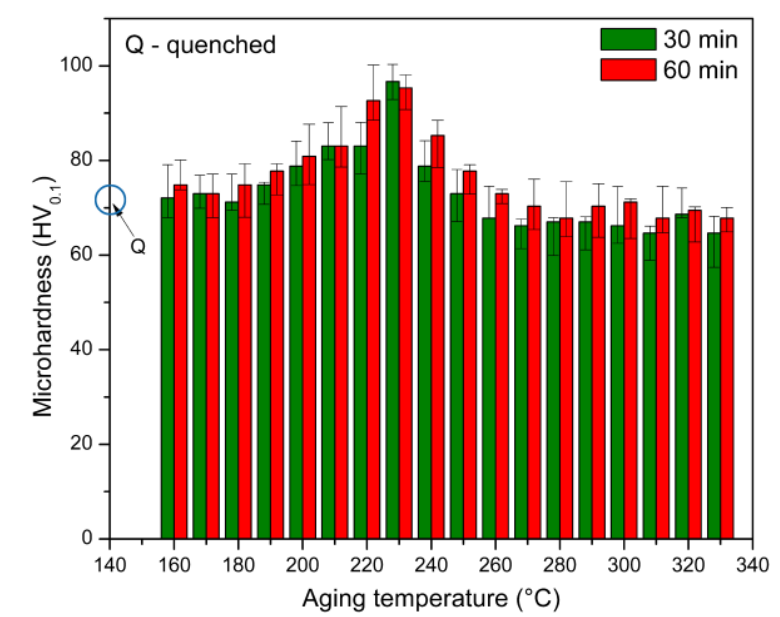

Fig. 3. Microhardness values of the EN AW-6060 alloy after the isochronal aging treatment.

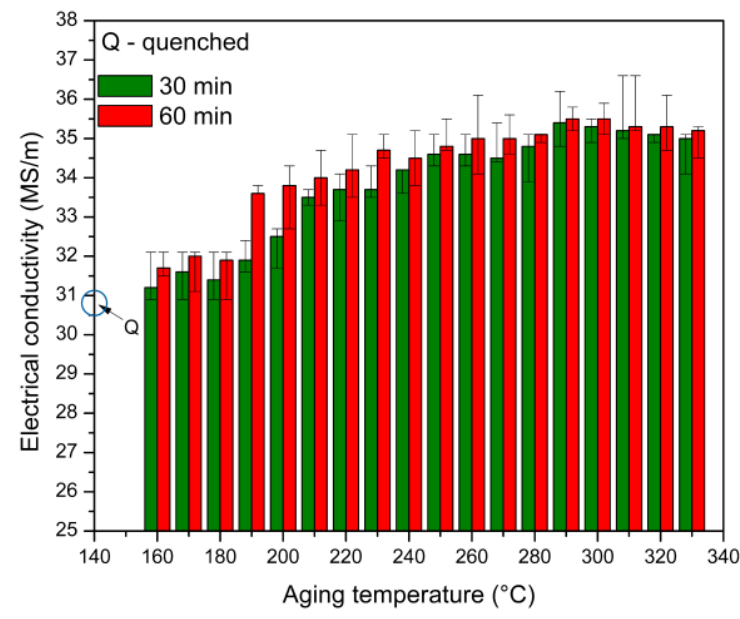

Fig. 4. Electrical conductivity values of the EN AW6060 alloy after the isochronal aging treatment.

Aging for 30 min caused a $26 \%$ relative increase in microhardness value compared to the quenched sample, i.e., microhardness increased from $77 \mathrm{HV}_{0.1}$ to $97 \mathrm{HV}_{0.1}$. When aged for $60 \mathrm{~min}$ there was a $19 \%$ relative increase in microhardness value compared to the quenched sample, i.e., microhardness increased from $77 \mathrm{HV}_{0.1}$ to $95 \mathrm{HV}_{0.1}$. Overaging is particularly well illustrated in the part of the diagram covering the temperature range from 260 ${ }^{\circ} \mathrm{C}$ to $330{ }^{\circ} \mathrm{C}$. In this case, almost all of the microhardness values of the aged samples are lower than those of the quenched one.

\section{Investigation of electrical conductivity}

The electrical conductivity values obtained during the isochronal aging treatment are presented in Fig. 4. The measurement of electrical conductivity can indirectly give information about precipitation, especially in $\mathrm{Al}-\mathrm{Mg}-\mathrm{Si}$ alloys where a strong connection between electrical conductivity and precipitation exists [22, 23].

The electrical conductivity of the quenched sample is $30.8 \mathrm{MS} / \mathrm{m}$. Quenching caused the 
increase in vacancies and solutes in the matrix causing the electron scattering effect [13, 23, 24]. During the aging, clusters and early-stage precipitates coarsen as a result of the diffusion process, which causes a gradual increase in electrical conductivity values. The metastable $\beta$," and $\beta$ ' are formed, causing the dilution of the solid solution resulting in electrical conductivity increase $[22,23]$.

The electrical conductivity peak values are achieved at $290{ }^{\circ} \mathrm{C}$ for both aging times. The absolute increase in electrical conductivity is 4.6 $\mathrm{MS} / \mathrm{m}$ during the aging at $290{ }^{\circ} \mathrm{C}$ for $30 \mathrm{~min}$ and 4.7 MS/m during the aging for $60 \mathrm{~min}$. Aging for a longer time $(60 \mathrm{~min})$ caused higher electrical conductivity values than the shorter aging time (30 min). Prolonged aging time increases the precipitations dissolution and causes the easier formation of pre- $\beta$ "' and $\beta$ " phases [23].

\section{Investigation of thermal properties}

Fig. 5 shows the thermal diffusivity of the quenched EN AW-6060 alloy during continuous heating at the rate of $10{ }^{\circ} \mathrm{C} \mathrm{min}-1$.

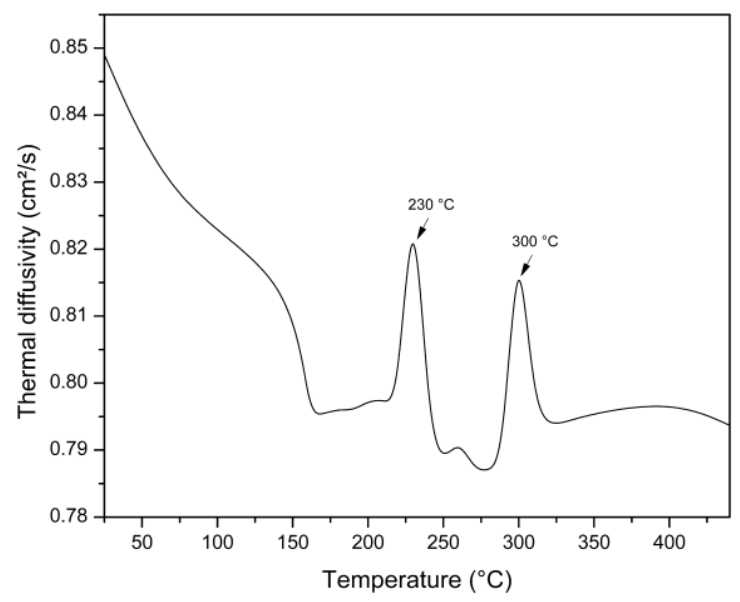

Fig. 5. Thermal diffusivity of quenched EN AW6060 alloy during the continuous heating.

Usually, with an increase in temperature thermal diffusivity linearly decreases. This is caused by heat vibrations of the atoms in the matrix that interrupt the movements of electrons [25].

However, in Fig. 5 two peaks at $230{ }^{\circ} \mathrm{C}$ and 300 ${ }^{\circ} \mathrm{C}$ can be observed. The temperatures of the peaks coincide with the temperatures where the maximal values of hardness and electrical conductivity were obtained during the aging. Hence, the diffusivity peaks are the proof that metastable phases have an influence on thermophysical properties. The first peak that appears at $230{ }^{\circ} \mathrm{C}$ represents the formation of $\beta$ " precipitates. The second peak that appears at $300{ }^{\circ} \mathrm{C}$ is related to the formation of $\beta$ ' phase. Heat transfer is increased because the concentration of alloying elements in the solid solution is reduced $[8,9]$. Peaks that represent the formation of clusters and excess $\mathrm{Si}$ are not registered on the thermal diffusivity curve. This is most probably due to the fact that the thermal diffusivity measurements are not sensitive enough to register such small change in the structure, unlike the measurements in DSC analysis.

Thermal diffusivity and thermal conductivity were measured at room temperature after aging at $160{ }^{\circ} \mathrm{C}, 230{ }^{\circ} \mathrm{C}$ and $330{ }^{\circ} \mathrm{C}$. These temperatures were chosen to represent three different stages in the precipitation process. G.P. zones were formed at the lowest chosen temperature; metastable phases were formed at the medium chosen temperature, while the highest chosen temperature indicates over-aging. The measured values of thermal diffusivity and thermal conductivity in the function of the aging temperature are given in Fig. 6. The presented results demonstrate that aging has an influence on the thermal properties.

Aging at $160{ }^{\circ} \mathrm{C}$ caused a decrease in thermal diffusivity and thermal conductivity values compared to the quenched state. This can be ascribed to the strong electron scattering effect caused by the formation of closely spaced G.P. zones and fine early-stage precipitates [13, 23, 26]. The highest values of thermal diffusivity were obtained at $230{ }^{\circ} \mathrm{C}$ for both aging times, as well as the values of hardness and microhardness.

This increase is also evident in Fig. 5 and is related to the formation of $\beta$ ' 'precipitates. Aging at $330{ }^{\circ} \mathrm{C}$ caused a slight decrease in thermal diffusivity as a result of the precipitation of semicoherent $\beta$ ' particles. During aging, thermal conductivity continuously increased up to $330{ }^{\circ} \mathrm{C}$ for the samples aged for $30 \mathrm{~min}$. The thermal conductivity curve for the sample aged for $60 \mathrm{~min}$ follows the same trend as the curves for thermal diffusivity.

\section{Microstructural investigation}

In order to complete the investigation in more detail and study the effect of the aging process on the alloy's microstructure, SEM and EDS analysis were performed on the sample in peak hardness state, as presented in Fig. 7. It can be seen that the solid solution matrix is covered with finely dispersed particles of the metastable $\beta$ " phase, represented by the spectrum 3 in Fig. 7. Marioara et al. $[20,27]$ suggested that the ideal ratio of $\mathrm{Mg}: \mathrm{Si}$ in the $\beta$ " phase should be 5 to 6 , as presented in our analysis. It is very difficult to detect the ultra-fine particles of the $\beta$ " phase at these magnifications; however, the other results obtained in this study indirectly indicate their existence. This indication is evident through the hardness and microhardness 
U. Stamenkovic et al.:The influence of isochronal aging on the mechanical and thermophysical properties of ... measurements that are enhanced by the precipitation of $\beta$ " phase after aging at $230{ }^{\circ} \mathrm{C}$.


Fig. 6. Thermal diffusivity (a) and thermal conductivity (b) of EN AW-6060 alloy as a function of aging temperature

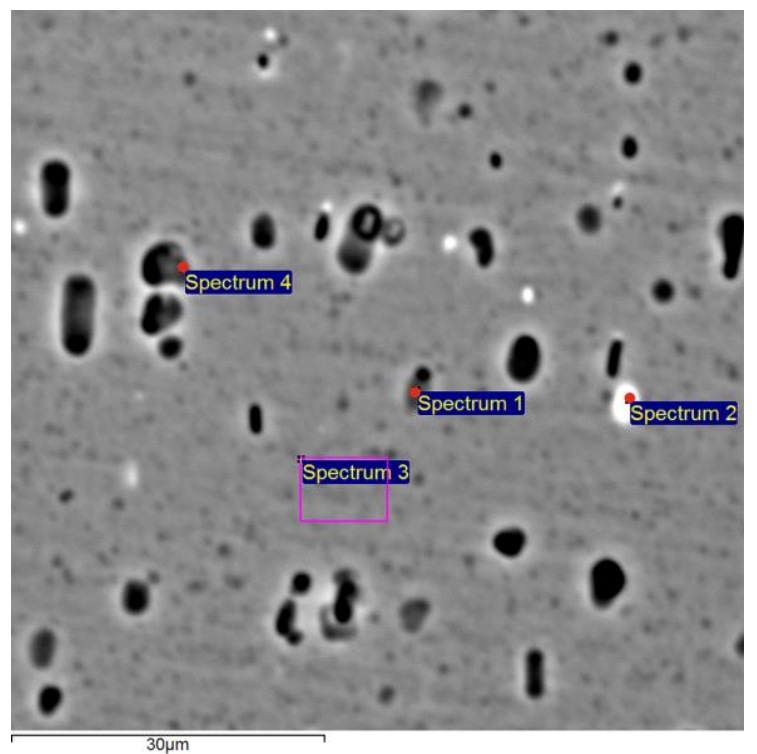

Fig. 7. SEM and EDS analyses of EN AW-6060 alloy after aging at $230^{\circ} \mathrm{C}$ for $30 \mathrm{~min}$

Table 2. Chemical composition of the analyzed spectra (at. \%)

\begin{tabular}{ccccc}
\hline Spectrum & $\mathrm{Mg}$ & $\mathrm{Al}$ & $\mathrm{Si}$ & $\mathrm{Fe}$ \\
\hline Spectrum 1 & 0.58 & 98.36 & 1.06 & \\
\hline Spectrum 2 & 0.51 & 95.55 & 1.48 & 2.46 \\
\hline Spectrum 3 & 0.50 & 98.93 & 0.57 & \\
\hline Spectrum 4 & 0.48 & 98.4 & 1.12 & \\
\hline
\end{tabular}

Within the presented microstructure in Fig. 7 the precipitates that appear as a dark phase can be observed. This phase is illustrated by the spectra 1 and 4 and its chemical composition is provided in Table 2. There is also an additional white phase that appears throughout the microstructure. This is the quaternary AlMgSiFe phase, especially rich in iron represented by spectrum 2 .

\section{CONCLUSIONS}

Based on the results obtained during the study of the influence of isochronal aging on the mechanical and thermophysical properties of the EN AW-6060 aluminum alloy, the following conclusions were drawn:

- Largely accepted precipitation sequence due to the precipitation of metastable phases (which is: $\alpha_{\text {ssss }} \rightarrow \mathrm{Mg}: \mathrm{Si}$ clusters $\rightarrow$ G.P. zones $\rightarrow \beta$ ' $\rightarrow$ 
$\beta \rightarrow \beta)$ was detected by the presence of exothermic peaks during the DSC analysis.

- Isochronal aging caused significant increase in mechanical and physical properties. The highest improvement in hardness and microhardness values was obtained after aging at $230{ }^{\circ} \mathrm{C}$ by the precipitation of metastable $\beta$ "' phase. The formation of metastable $\beta^{\prime \prime}$ and $\beta^{\prime}$ phases caused the solid solution matrix to get less saturated, which increased electrical conductivity.

- Thermal diffusivity peaks obtained during the continuous heating confirmed the existence of $\beta$ ' and $\beta$ ' precipitates. The highest values of thermal diffusivity and thermal conductivity were obtained at $230^{\circ} \mathrm{C}$ for both aging times.

- Microstructural investigation confirmed the existence of finely dispersed metastable $\beta$ " phase with the ideal ratio of $\mathrm{Mg}: \mathrm{Si}=5: 6$, which caused the enhancement of physical, thermal and mechanical properties.

Acknowledgement: The research results were developed with the assistance of the Ministry of Education, Science and Technological Development of the Republic of Serbia under the projects OI 172037 and TR34003.

\section{REFERENCES}

1. K. Teichmann, C. D. Marioara, K. O. Marioara, K.O. Pedersen, K. Marthinsen, Mater. Sci. Eng., A, 565, 228 (2013).

2. M. Kolar, K.O. Pedersen, S. Gulbrandsen-Dahl, K. Teichmann, K. Marthinsen, Mater. Trans., 52, 1356 (2011).

3. I.M. Masoud, T. Abu Mansour, J.A. Al-Jarrah, Journal of Applied Sciences Research, 8, 5106 (2012).

4. S. Pogatscher, H. Antrekowitsch, T. Ebner, P.J. Uggowitzer, in: Light Metals, C. E. Suarez (ed.), Springer, Cham, 2012, p. 415.

5. T. Abid, A. Boubertakh, S. Hamamda, J. Alloy. Compd., 490, 166 (2010).
6. K. Strobel, M.D.H. Lay, M.A. Easton, L. Sweet, S. Zhu, N.C. Parson, A.J. Hill, Mater. Charact., 111, 43 (2016).

7. B. Milkerit, N. Wanderka, C. Schick, O. Kessler, Mater. Sci. Eng., A, 550, 87 (2012).

8. Y.M. Kim, S.W. Choi, Y.C. Kim, C.S. Kang, S.K. Hong, Appl. Sci., 8, 2039 (2018).

9. S.W. Choi, Y.M. Kim, Y.C. Kim, J. Alloy. Compd., 775, 132 (2019).

10. https://www.astm.org/Standards/E384.htm

11. Y. Birol, Trans. Nonferrous Met. Soc. China, 23, 1875 (2013).

12. A.K. Gupta, D.J. Lloyd, S.A. Court, Mater. Sci. Eng., A, 316, 11 (2001).

13. G.A. Edwards, K. Stiller, G.L. Dunlop, M.J. Couper, Acta Mater., 46, 3893 (1998).

14. B.C. Shang, Z.M. Yin, G. Wang, B. Liu, Z.Q. Huang, Mater. Design., 32, 3818 (2011).

15. M. Vedani, G. Angella, P. Bassani, D. Ripamonti, A. Tuissi, J. Therm. Anal. Calorim., 87, 277 (2007).

16. L. Zhen, W.D. Fei, S.B. Kang, H.W. Kim, J. Mater. Sci., 32, 1895 (1997).

17. Y. Birol, J. Mater. Process. Tech., 173, 84 (2006).

18. S.W. Choi, H.S. Cho, C.S. Kang, S. Kumai, J. Alloy. Compd., 647, 1091 (2015).

19. C.D. Marioara, S.J. Andersen, J. Jansen, H.W. Zandbergen, Acta Mater., 49, 321 (2001).

20. C.D. Marioara, S.J. Andersen, J. Jansen, H.W. Zandbergen, Acta Mater., 51, 789 (2003).

21. O.R. Myhr, O. Grong, K.O. Pedersen, Metall. Mater. Trans. A, 41A, 2276 (2010).

22. S. Karabay, Mater. Design, 27, 821 (2006).

23. L. Cui, Z. Liu, Xi. Zhao, J. Tang, K. Liu, X. Liu, C. Qian, Trans. Nonferrous Met. Soc. China, 24, 2266 (2014).

24. T.R. Prabhu, Engineering Science and Technology, an International Journal, 20, 133 (2017).

25. T.M. Tritt, Thermal Conductivity: Theory, Properties and Applications, Kluwer Academic /Plenum Publisher, New York, 2004.

26. R.G. Lumley, N. Deeva, R. Larsen, J. Gemberovic, J. Freeman, Metall. Mater. Trans. A, 44, 1074 (2013).

27. C.D. Marioara, H. Nordmark, S.J. Andersen, R. Holmestad, Mater. Sci., 41, 471 (2006). 